\title{
SHORT TERM OUTCOMES IN TERM NEWBORNS TRANSFERRED FOR RESPIRATORY DISTRESS AND/OR FAILURE FROM PRIMARY AND SECONDARY CARE CENTERS
}

\author{
M. Tsapis ${ }^{1}$, F. Kieffer ${ }^{2}$, V. Henry-Larzul ${ }^{3}$, M. Goulet ${ }^{4}$, H. Arbaoui ${ }^{4}$, A. Ayachi ${ }^{4}$ \\ ${ }^{1}$ Pediatric Transport Team Montreuil Hospital, SAMU 93, Hopital Avicenne, AP-HP, Faculté Paris 13, \\ Bobigny, Montreuil, ${ }^{2}$ Institut de Puériculture de Paris, Paris, ${ }^{3}$ Pediatric Transport Team Pontoise Hospital, \\ SAMU 95, Pontoise, ${ }^{4}$ Pediatric Transport Team Montreuil Hospital, SAMU 93, Hopital Avicenne, AP-HP, \\ Faculté, Montreuil, France
}

Objective: Describe mortality and short term morbidity in term newborns transferred from type 1 and type 2 perinatal care centers for respiratory distress and/or failure by specialized pediatric transport teams.

Design: Retrospective observational cohort study by review of transport and destination charts.

Setting: Two departmental specialized pediatric emergency mobile units.

Patients: Every term newborn less than three days of life transferred for respiratory distress and/or failure born at home or in type 1 and 2 perinatal care center during year 2007.

Main outcome measures: Mortality and invasive ventilation for more than five days.

Results: There were 247 transfers of term newborns for respiratory distress and/or failure corresponding to defined criteria. $66 \%$ concerned boys. Origin of respiratory symptoms was respiratory in $69 \%$, neurological in $22.4 \%$ and cardio-circulatory in $8.6 \%$ of cases. $70.4 \%$ of transferred newborns had severe respiratory distress and/or failure necessitating tracheal intubation. Death occurred in $8.6 \%$, with neurological origin of respiratory failure and low birth weight being two independent factors associated with mortality. Invasive ventilation for more than 5 days was present for $19 \%$ of transferred newborns and $27 \%$ of intubated newborns. Neurological origin of respiratory distress and/or failure, masculine sex and time from the beginning of respiratory symptoms to intubation were three independent factors associated with tracheal ventilation for more than five days.

Conclusion: Respiratory distress and/or failure in term newborns transferred from type 1 and 2 perinatal care centers is associated with significant mortality and short term morbidity defined as invasive ventilation for more than five days. 